\title{
Original
}

[Joumal of Environmental Chemistry Vol.10, No.2, pp. 273-280, 2000]

\section{Characterization and Determination of Halogenated Organic Compounds in River Water and Drinking Water}

\author{
Yasuo TAKAHASHI'), Sukeo ONODERA ${ }^{2)}$ and Masatoshi MORITA ${ }^{3)}$ \\ 1) The Tokyo Metropolitan Research Laboratory of Public Health \\ (3-24-1 Hyakunincho, Shinjuku-ku, Tokyo 169-0073) \\ ${ }^{2)}$ Faculty of Pharmaceutical Science, Tokyo University of Science \\ (12 Ichigaya-Funagawara-machi, Shinjuku-ku, Tokyo 162-0826) \\ ${ }^{3)}$ National Institute for Environmental Studies \\ (16-2 Onogawa, Tsukuba, Ibaraki 305-0053)
}

[Received July 29, 1999]

\begin{abstract}
Summary
Water samples collected from $\mathrm{TE}$ river and $\mathrm{K}$ drinking water supply system which takes water from the TE river were analyzed by means of $\mathrm{GC} / \mathrm{ECD}$, in order to characterize and determine halogenated organic compounds. Trihalomethanes, haloacetones, haloacetaldehydes, haloacetic acids, halopropionic acids were found to be present in both river and drinking water. Among these halogenated organics, the highest concentration was observed for haloacetic acids in the river water while haloacetic acids and trihalomethanes as disinfection by-products were detected at higher concentrations in the drinking water. Brominated compounds, such as bromodichloromethane and tribromoacetic acid, were also detected at high concentrations in the drinking water, although these compounds showed very low levels in the river water.

These results were also compared with those observed for TA river and S drinking water which takes water from the TA river.
\end{abstract}

Key words: halogenated disinfection by:product, river water, drinking water, organohalogens

\section{INTRODUCTION}

The occurrence of halogenated organic compounds in water systems has received much attention in recent years. While some of the halogenated compounds arise from contamination from industrial discharges, agricultual sources, and runoff in the water sources, the practice of chlorination in treatment of potable water, wastewater and cooling water has also been demonstrated to result in the formation of new organic compounds ${ }^{1)}$. Of particular interest, because of their potential health significance, are the halogenated compounds in drinking water. Rook ${ }^{2)}$ and Beller et $\mathrm{al}^{3)}$. demonstrated that or- ganic compounds in raw water are halogenated by reaction with chlorine, producing trihalomethanes in the finished water.

Chloroform, the most common trihalomethane, has been shown to be rapidly adsorbed on oral and intravenous administration and subsequently metabolized to carbon dioxide, chloride ion, phosgene and other unidentified metabolites ${ }^{4)}$. Mammalian responses to chloroform exposure include central nervous system depression, hepatotoxicity, nephrotoxicity, teratogenicity and carcinogenicity. These responses are described in mammals after oral and inhalation exposures to high levels of chloroform ranging from $30 \sim 350 \mathrm{mg} / \mathrm{Kg}$, and the in- 
tensity of response depends upon the dose. Although trihalomethanes are of concern because of their effects on health and significant levels in water supplies ${ }^{4,5)}$, recent work ${ }^{6-9)}$ has shown that even higher levels of halogenated organic compounds, such as haloacetic acids, can be formed as the result of chlorination of natural water. It has also been shown that the mutagenic character of chlorinated drinking water is more closely associated with these halogenated organic compounds ${ }^{6)}$. In order to provide further insight into the possible role of organic compounds in the formation and elimination of halogen-incorporated compounds in water supply systems, we have continued the study of the aqueous chlorination chemistry and analytical chemistry of these compounds $^{10,11)}$. The purpose of this study is to characterize and quantify of trihalomethanes, haloacetones, haloacetaldehydes, haloacetic acids and other halogenated organics present in river waters as a source of potable water and drinking water. These findings provide back ground information that will be useful in assessing the health implications and trends of organic compound behavior in these rivers and drinking waters.

\section{EXPERIMENTAL METHODS}

\section{Reagents}

As previously reported ${ }^{10)}$, the following reagents were used as standards of halogenated compounds: haloacetonitriles, haloacetones, haloacetaldehydes, haloacetic acids and halopropionic acids (Hayashi Junyaku, Tokyo Kasei and Aldrich); trihalomethane standard solution and chloropicrin standard solution for water quality tests (Wako Pure Chemical Industries, Ltd.). The other reagents used were: hexane as extrac- tion solvent for water quality test (Wako Pure Chemi cal Industries, Ltd.), $t$-butyl methyl ether for liquid chromatography (MTBE, Nacalai Tesque, Inc.), sodium sulfate anhydride as a dehydrator for residual agricultural chemical tests (Wako Pure Chemical Industries, Ltd.), ascorbic acid for elimination of residual chlorine, $\mathrm{N}$-methyl-N'-nitro-N-nitrosoguanidine for preparation of diazomethane solution (Nacalai Tesque, Inc.), and sodium chloride as an analytical grade reagent (Wako Pure Chemical Industries, Ltd.). Sodium chloride was heated to about $450^{\circ} \mathrm{C}$ for about 6 hours before use.

\section{Sample collection}

Water samples were collected from the TE river at eight sampling stations and from the $\mathrm{K}$ drinking water supply system which takes water from this river in June and October 1995. Water samples were also collected from the TA river at six sampling sites and from the $\mathrm{S}$ drinking water supply system which takes water from this river in June and October 1996. S drinking water samples were also collected in June and October 1995. To avoid contamination, all utensils and containers were scrupulously cleaned and rinsed with deionized and distilled water before use. Each of these water samples was placed in an ice box and transported to the laboratory and then stored at $5^{\circ} \mathrm{C}$ for 1 day until subsequent organohalogen determination.

\section{Organohalogen determination}

As we previously reported ${ }^{10)}$, organic halogen compounds were determined using a GC/ECD (Hewlett Packard, 5890A) under the conditions shown in Table 1. The multi-component systematic analytical method for

Table 1 Apparatus and operational conditions of GC/ECD

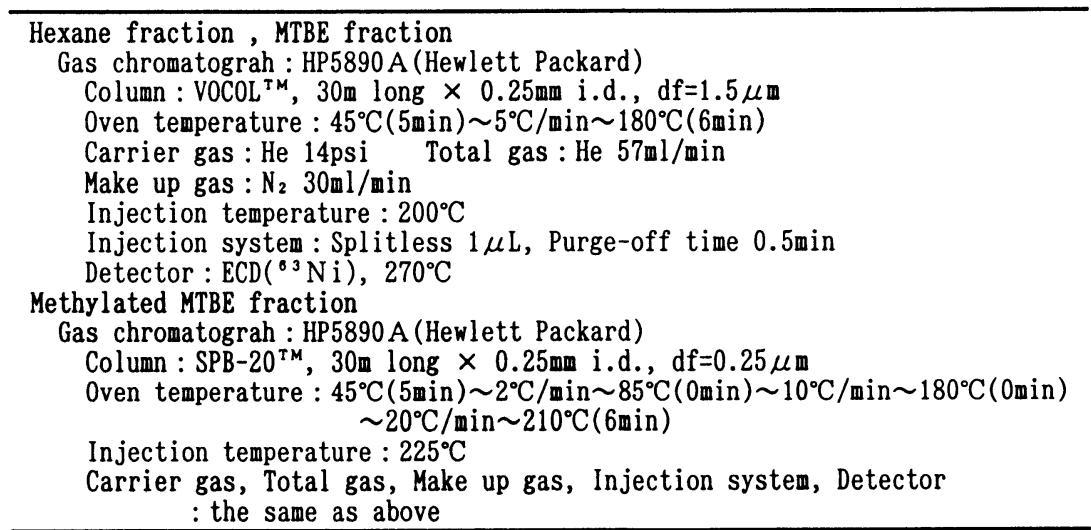


organic halogens in drinking water established in our previous work ${ }^{10)}$ was also used in this study. Residual chlorine in drinking water (each $40 \mathrm{~m} \ell$ ) was eliminated by addition of ascorbic acid. Before extraction with hexane ( $10 \mathrm{~m} \ell \times 2$ times), sodium chloride $(15 \mathrm{~g})$ was added into the water sample. After dehydration, the combined extracts were infused into a capillary column $\mathrm{GC} / \mathrm{ECD}$ for volatile organic halogen determinations.

The aqueous layer that extracted with hexane was mixed with sulfuric acid $(1+1)$ to adjust the $\mathrm{pH}$ to 0.5 or less before extraction with an MTBE $(2.5 \mathrm{~m} \ell \times 2$ times) for both volatile and non-volatile organic halogen analysis. Additional extraction with $\operatorname{MTBE}(10 \mathrm{~m} \ell)$ was also performed. The MTBE $(2.5 \mathrm{~m} \ell \times 2)$ fraction and other MTBE $(10 \mathrm{~m} \ell)$ fraction were dehydrated and infused into a capillary column GC/ECD for volatile organic halogen determinations. On the other hand, the dehydrated MTBE $(2.5 \mathrm{~m} \ell \times 2)$ fraction was methylated by diazomethane and infused into a capillary column $\mathrm{GC} / \mathrm{ECD}$ for non-volatile organohalogen determinations.

\section{RESULTS AND DISCUSSION}

\section{Halogenated organic compounds in TE river water and $K$ drinking water}

The minimum, maximum, and mean concentrations of each organohalogen and their detection frequencies in water samples collected from the TE river at eight sampling stations in June and October 1995 are sum.

Table 2 Minimum, maximum and mean concentrations of each organohalogen and their detection frequencies in water samples collected from the TE river at 8 sampling stations, and concentrations of each organohalogen in the $\mathrm{K}$ drinking water originating from the $\mathrm{TE}$ river

(Unit: $\mu \mathrm{g} / \mathrm{L}$ )

\begin{tabular}{|c|c|c|c|c|c|c|c|c|c|c|}
\hline \multirow{3}{*}{$\begin{array}{l}\text { TE River water } \\
\text { and } X \text { drinking water }\end{array}$} & \multicolumn{5}{|c|}{ Jun.26 1995} & \multicolumn{5}{|c|}{ 0ct.19 1995} \\
\hline & \multicolumn{4}{|c|}{ River water } & \multirow{2}{*}{$\begin{array}{l}\text { Drinking } \\
\text { water }\end{array}$} & \multicolumn{4}{|c|}{ River water } & \multirow{2}{*}{$\begin{array}{c}\text { Drinking } \\
\text { water }\end{array}$} \\
\hline & Min. & $\operatorname{Max}$. & Mean & Frequency & & Min. & Max. & Mean & Frequency & \\
\hline Total organic halogen & 1.0 & 8.2 & 3.64 & $8 / 8$ & 53.6 & 2.9 & 9.0 & 4.20 & $8 / 8$ & 69.8 \\
\hline [Trihalonethanes] & nd & 0.5 & 0.21 & $5 / 8$ & 14.2 & nd & 1.4 & 0.24 & $5 / 8$ & 20.8 \\
\hline Chlorofor & nd & 0.5 & 0.20 & $5 / 8$ & 5.0 & nd & 1.2 & 0.20 & $4 / 8$ & 4.7 \\
\hline Bromodichloromethane & nd & 0.1 & 0.01 & $1 / 8$ & 5.3 & nd & 0.1 & 0.01 & $1 / 8$ & 7.7 \\
\hline Dibronochloronethane & nd & nd & nd & $0 / 8$ & 3.4 & nd & 0.1 & 0.03 & $2 / 8$ & 7.0 \\
\hline Bromoforn & nd & nd & nd & $0 / 8$ & 0.5 & nd & nd & nd & $0 / 8$ & 1.4 \\
\hline [Haloacetonitriles] & nd & nd & nd & $0 / 8$ & 3.2 & nd & nd & nd & $0 / 8$ & 5.2 \\
\hline Chloroacetonitrile & nd & nd & nd & $0 / 8$ & nd & nd & nd & nd & $0 / 8$ & nd \\
\hline Dichloroacetonitrile & nd & nd & nd & $0 / 8$ & 2.0 & nd & nd & nd & $0 / 8$ & 2.4 \\
\hline Bromochloroacetonitrile & nd & nd & nd & $0 / 8$ & 0.9 & nd & nd & nd & $0 / 8$ & 1.7 \\
\hline Dibromoacetonitrile & nd & nd & nd & $0 / 8$ & 0.3 & nd & nd & nd & $0 / 8$ & 1.1 \\
\hline Trichloroacetonitrile & nd & nd & nd & $0 / 8$ & nd & nd & nd & nd & $0 / 8$ & nd \\
\hline [Haloacetones] & 0.4 & 0.9 & 0.60 & $8 / 8$ & 2.3 & 1.2 & 2.2 & 1.78 & $8 / 8$ & 3.4 \\
\hline Chloroace tone & 0.4 & 0.9 & 0.60 & $8 / 8$ & 1.0 & 0.9 & 1.8 & 1.44 & $8 / 8$ & 1.1 \\
\hline Bromoacetone & nd & nd & nd & $0 / 8$ & 0.3 & nd & 0.6 & 0.34 & $7 / 8$ & 1.0 \\
\hline 1,1-Dichloroacetone & nd & nd & nd & $0 / 8$ & 0.2 & nd & nd & nd & $0 / 8$ & 0.4 \\
\hline 1,3-Dichloroacetone & nd & nd & nd & $0 / 8$ & nd & nd & nd & nd & $0 / 8$ & nd \\
\hline 1,1,1-Trichloroacetone & nd & nd & nd & $0 / 8$ & 0.7 & nd & nd & nd & $0 / 8$ & 0.9 \\
\hline $1,1,3$-Trichloroace tone & nd & nd & nd & $0 / 8$ & 0.1 & nd & nd & nd & $0 / 8$ & nd \\
\hline [Halonitronethanes] & nd & nd & nd & $0 / 8$ & nd & nd & nd & nd & $0 / 8$ & nd \\
\hline Chloropicrin & nd & nd & nd & $0 / 8$ & nd & nd & nd & nd & $0 / 8$ & nd \\
\hline [Hal oacetaldehydes] & nd & nd & nd & $0 / 8$ & 3.2 & nd & 0.2 & 0.06 & $3 / 8$ & 6.1 \\
\hline Chloroacetaldehyde & nd & nd & nd & $0 / 8$ & nd & nd & nd & nd & $0 / 8$ & nd \\
\hline Dichloroacetaldehyde & nd & nd & nd & $0 / 8$ & 0.5 & nd & 0.2 & 0.06 & $3 / 8$ & 0.5 \\
\hline Trichloroacetaldehyde & nd & nd & nd & $0 / 8$ & 2.7 & nd & nd & nd & $0 / 8$ & 5.3 \\
\hline Tribromoacetaldehyde & - & - & - & - & - & nd & nd & nd & - & 0.3 \\
\hline [Haloacetic acids] & 0.3 & 6.6 & 2.65 & $8 / 8$ & 30.7 & 1 & 5.9 & 2.19 & $8 / 8$ & 33.7 \\
\hline Chloroacetic acid & nd & nd & nd & $0 / 8$ & nd & nd & nd & nd & $0 / 8$ & nd \\
\hline Bromoacetic acid & nd & nd & nd & $0 / 8$ & 0.2 & nd & nd & nd & $0 / 8$ & 0.4 \\
\hline Dichloroacetic acid & 0.3 & 1.9 & 0.90 & $8 / 8$ & 9.1 & 0.2 & 1.2 & 0.50 & $8 / 8$ & 8.1 \\
\hline Bromochloroacetic acid & nd & 0.1 & 0.03 & $2 / 8$ & 3.6 & nd & 0.1 & 0.01 & $1 / 8$ & 4.2 \\
\hline Dibromoacetic acid & nd & nd & nd & $0 / 8$ & 2.3 & nd & nd & nd & $0 / 8$ & 4.1 \\
\hline Trichloroacetic acid & nd & 4.8 & 1.63 & $7 / 8$ & 6.0 & 0.5 & 3.7 & 1.11 & $8 / 8$ & 6.1 \\
\hline Dichlorobronoacetic acid & nd & 0.4 & 0.10 & $3 / 8$ & 1.3 & nd & 0.3 & 0.13 & $6 / 8$ & 2.5 \\
\hline Dibronochloroacetic acid & nd & nd & nd & $0 / 8$ & 0.9 & 0.3 & 0.7 & 0.44 & $8 / 8$ & 2.4 \\
\hline Tribrosoacetic acid & nd & nd & nd & $0 / 8$ & 7.3 & nd & nd & nd & $0 / 8$ & 5.9 \\
\hline [Halopropionic acids] & nd & 0.7 & 0.18 & $3 / 8$ & 0.5 & nd & 0.2 & 0.06 & $3 / 8$ & 0.6 \\
\hline$\alpha$-Chloropropionic acid & nd & nd & nd & $0 / 8$ & nd & nd & nd & nd & $0 / 8$ & nd \\
\hline$\alpha$-Bromopropionic acid & nd & nd & nd & $0 / 8$ & nd & nd & nd & nd & $0 / 8$ & 0.1 \\
\hline$\beta$-Bromopropionic acid & nd & nd & nd & $0 / 8$ & nd & nd & nd & nd & $0 / 8$ & nd \\
\hline 2,2-Dichloropropionic acid & nd & 0.7 & 0.18 & $3 / 8$ & 0.4 & nd & 0.2 & 0.03 & $1 / 8$ & 0.4 \\
\hline 2,3-Dichloropropionic acid & nd & nd & nd & $0 / 8$ & 0.1 & nd & 0.2 & 0.04 & $2 / 8$ & 0.1 \\
\hline
\end{tabular}

$\mathrm{K}$ drinking water is approxinately half by half nixture of water fron conventional water treatnent plant, where water is treated with flocculation, sedinentation and sand filtration, and water fron further advanced treatment plant, both waters are derived fron the TE river. 
marized in Table 2. The $\mathrm{K}$ drinking water is ap proximately half by half mixture of water from conven tional water treatment plant, where water is treated with flocculation, sedimentation and sand filtration, and water from further advanced treatment plant. Both waters are derived from the TE river. The concentrations of or ganohalogens in the $\mathrm{K}$ drinking water are summarized in Table 2. In addition, the compositions of or ganohalogens quantified in the river and drinking waters are presented graphically in Fig. 1 as a circular diag. ram for each component.

Trihalomethanes, haloacetones, haloacetaldehydes, haloacetic acids and halopropionic acids were detected in these water samples collected from the TE river, although no haloacetaldehydes were quantified in the June-river water. Also no haloacetnitriles and halonitromethanes were detected in the river water samples collected in June and October 1995. The total concentration of organohalogens in these river waters was approximately $4 \mu \mathrm{g} / \ell$. Among these halogenated organics quantified, the highest concentration was found to be haloacetic acids in river waters as sampled in June and October 1995. About 89 and $94 \%$ of the total amount of organic halogens detected in the June-river and Oc-

\section{TE River water, Jun.1995}

5.8\% Trihalomethane

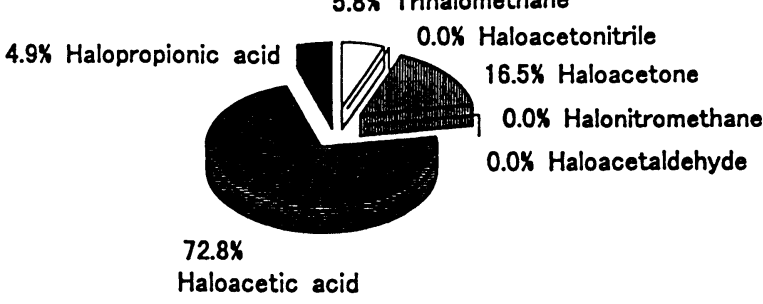

TE River water, Oct.1995

5.7x Trihalomethane

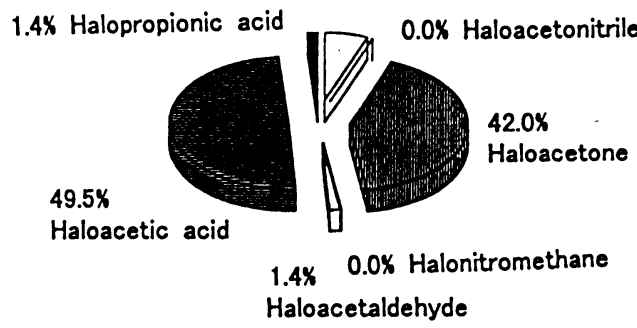

tober-river waters can be accounted for by the presence of haloacetones and haloacetic acids, respectively (Fig. 1). In addition, the TE river water as sampled in October 1995 was characterized by a higher concentration of haloacetones, compared with those observed for other halogenated organics.

High concentrations of chlorinated organics such as chloroform, chloroacetone, dichloroacetaldehyde, trichloroacetic acid were generally observed in the river water, as compared with those detected for brominated compounds. Chloroacetone has been shown to be present at high concentrations in pool water ${ }^{12)}$ and drinking water derived from a certain source ${ }^{13)}$. In the present work, higher concentrations of trihalomethanes and haloacetic acids were also observed for the river water collected from a certain site, near wastewater discharge from densely populated areas. Therefore, some of these organohalogens detected in the TE river seem to arise from contamination from industrial discharge, agricultural sources, and domestic and medical wastewaters.

As expected from the previous works ${ }^{7.9)}$ and the literature ${ }^{8)}$, trihalomethanes, haloacetnitriles, haloacetones, haloacetaldehydes, haloacetic acids and halopropionic acids were detected at comparatively high concentra-

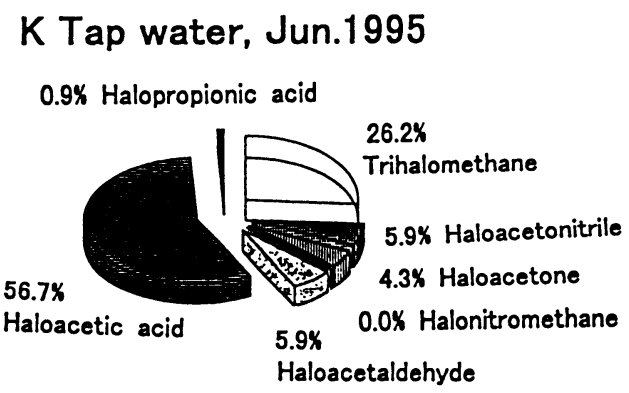

\section{K Tap water, Oct.1995}

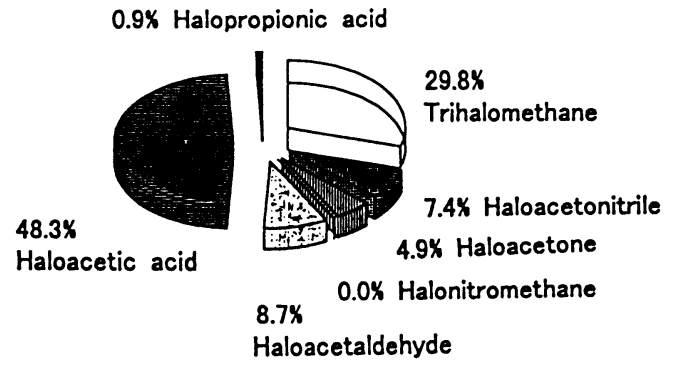

Fig. 1 Circular diagrams for concentration(\%) of each organohalogen group in the TE river water and the $\mathrm{K}$ drinking water originating from the TE river 
tions in the $\mathrm{K}$ drinking water as sampled in June and October 1995. No chloropicrin as the halonitromethane was quantified in these $\mathrm{K}$ drinking waters. Brominated compounds, such as bromodichloromethane and tribromoacetic acid, were also detected at high concentration in the $\mathrm{K}$ drinking water, although these compounds were very low in the TE river waters. The total concentrations of halogenated organics in the $\mathrm{K}$ drinking water samples were found to be approximately 15-times higher than those detected in the TE river waters. Among these compounds detected, trihalomethanes and haloacetic acids were found to be main disinfection by-products, while other halogenated organics were minor ones (Table 2 and Fig. 1).

\section{Halogenated organic compounds in TA river water and $S$ drinking water}

Minimum, maximum, and mean concentration of each halogenated organic compound and their detection frequencies in water samples collected from $\mathrm{TE}$ river at six sampling sites in June and October 1996 are summarized in Table 3. The concentrations of each halogenated organic compound in S drinking water which originated from the TA river are also summarized in Table 3. In addition, the compositions of organohalogens quantified in the river waters and drinking waters are presented graphically in Fig. 2 as a circular diagram for each group together with those observed in the TA river water samples.

As Table 3 shows, trihalomethanes, haloacetones,

Table 3 Minimum, maximum and mean concentrations of each halogenated organic compound and their detection frequencies in water samples collected from the TA river at 6 sampling stations, and concentrations of each halogenated organic compound in the $\mathrm{S}$ drinking water originating from the TA river

(Unit: $\mu \mathrm{g} / \mathrm{L}$ )

\begin{tabular}{|c|c|c|c|c|c|c|c|c|c|c|}
\hline \multirow{3}{*}{$\begin{array}{l}\text { TA River water } \\
\text { and } S \text { drinking water }\end{array}$} & \multicolumn{5}{|c|}{ Jun. 101996} & \multicolumn{5}{|c|}{ Oct. 251996} \\
\hline & \multicolumn{4}{|c|}{ River water } & \multirow{2}{*}{$\begin{array}{l}\text { Drinking } \\
\text { vater }\end{array}$} & \multicolumn{4}{|c|}{ River vater } & \multirow{2}{*}{$\begin{array}{l}\text { Drinking } \\
\text { water }\end{array}$} \\
\hline & Min. & Max. & Mean & Frequency & & Min. & Max. & Kean & $\overline{\text { Frequency }}$ & \\
\hline Total organic halogen & 2.2 & 13.2 & 4.83 & $6 / 6$ & 126.8 & 2.9 & 4.2 & 3.45 & $6 / 6$ & 95.8 \\
\hline [Tribalonethanes] & nd & 0.1 & 0.02 & $1 / 6$ & 25.8 & nd & 0.3 & 0.13 & $4 / 6$ & 32.4 \\
\hline Chloroforn & nd & 0.1 & 0.02 & $1 / 6$ & 15.0 & nd & 0.2 & 0.07 & $3 / 6$ & 10.7 \\
\hline Bromodichlorome thane & nd & nd & nd & $0 / 6$ & 8.0 & nd & 0.1 & 0.02 & $1 / 6$ & 12.7 \\
\hline Dibronochlorone thane & nd & nd & nd & $0 / 6$ & 2.6 & nd & 0.1 & 0.03 & $2 / 6$ & 8.0 \\
\hline Bromoform & nd & nd & nd & $0 / 6$ & 0.2 & nd & 0.1 & 0.02 & $1 / 6$ & 1.0 \\
\hline [Haloacetonitriles] & 0.1 & 0.3 & 0.18 & $6 / 6$ & 7.6 & nd & 0.7 & 0.30 & $5 / 6$ & 8.2 \\
\hline Chloroacetonitrile & nd & nd & nd & $0 / 6$ & 0.1 & nd & 0.2 & 0.03 & $1 / 6$ & 0.1 \\
\hline Dichloroacetonitrile & nd & nd & nd & $0 / 6$ & 5.4 & nd & 0.1 & 0.03 & $2 / 6$ & 4.2 \\
\hline Bronochloroacetonitrile & nd & nd & nd & $0 / 6$ & 1.5 & nd & 0.1 & 0.02 & $1 / 6$ & 2.6 \\
\hline Dibronoacetonitrile & 0.1 & 0.3 & 0.18 & $6 / 6$ & 0.6 & nd & 0.2 & 0.08 & $3 / 6$ & 1.3 \\
\hline Trichloroacetonitrile & nd & nd & nd & $0 / 6$ & nd & nd & 0.6 & 0.10 & $1 / 6$ & nd \\
\hline [Haloacetones] & 0.5 & 1.5 & 0.72 & $6 / 6$ & 3.8 & 0.6 & 1 & 0.88 & $6 / 6$ & 2.4 \\
\hline Chloroacetone & 0.4 & 0.7 & 0.53 & $6 / 6$ & 0.5 & 0.4 & 0.8 & 0.68 & $6 / 6$ & 0.5 \\
\hline Bronoacetone & nd & 0.1 & 0.05 & $3 / 6$ & nd & 0.1 & 0.1 & 0.10 & $6 / 6$ & nd \\
\hline 1,1-Dichloroacetone & nd & nd & nd & $0 / 6$ & 0.2 & nd & nd & nd & $0 / 6$ & 0.1 \\
\hline 1,3-Dichloroacetone & nd & 0.2 & 0.03 & $1 / 6$ & nd & nd & nd & nd & $0 / 6$ & nd \\
\hline 1,1,1-Trichloroace tone & nd & nd & nd & $0 / 6$ & 2.9 & nd & nd & nd & $0 / 6$ & 1.7 \\
\hline $1,1,3$-Trichloroace tone & nd & 0.5 & 0.10 & $2 / 6$ & 0.2 & 0.1 & 0.1 & 0.10 & $6 / 6$ & 0.1 \\
\hline [Halonitronethanes] & nd & nd & nd & $0 / 6$ & 0.3 & nd & nd & nd & $0 / 6$ & 0.2 \\
\hline Chloropicrin & nd & nd & nd & $0 / 6$ & 0.3 & nd & nd & nd & $0 / 6$ & 0.2 \\
\hline [Hal oacetaldehydes] & 0.4 & 4.6 & 1.31 & $6 / 6$ & 16.9 & 0.8 & 1.5 & 1.22 & $6 / 6$ & 12.3 \\
\hline Chloroacetaldehyde & nd & nd & nd & $0 / 6$ & 0.1 & 0.1 & 0.2 & 0.13 & $6 / 6$ & 0.1 \\
\hline Dichloroacetaldehyde & 0.3 & 4.5 & 1.28 & $6 / 6$ & 2.2 & 0.6 & 1.0 & 0.75 & $6 / 6$ & 1.5 \\
\hline Trichloroacetaldehyde & nd & 0.1 & 0.03 & $2 / 6$ & 14.6 & nd & 0.1 & 0.08 & $5 / 6$ & 10.5 \\
\hline Tribromoacetaldehyde & - & - & - & - & - & nd & 0.6 & 0.25 & $3 / 6$ & 0.2 \\
\hline [Haloacetic acids] & 0.6 & 7.2 & 2.22 & $6 / 6$ & 66.9 & 0.7 & 1.4 & 0.92 & $6 / 6$ & 39.5 \\
\hline Chloroacetic acid & nd & nd & nd & $0 / 6$ & 2.7 & nd & nd & nd & $0 / 6$ & 0.6 \\
\hline Bromoacetic acid & nd & nd & nd & $0 / 6$ & nd & nd & nd & nd & $0 / 6$ & 0.2 \\
\hline Dichloroacetic acid & nd & nd & nd & $0 / 6$ & 29.1 & 0.2 & 0.4 & 0.28 & $6 / 6$ & 12.3 \\
\hline Bromochloroacetic acid & nd & nd & nd & $0 / 6$ & 6.5 & nd & nd & and & $0 / 6$ & 5.1 \\
\hline Dibronoacetic acid & nd & nd & nd & $0 / 6$ & 1.3 & nd & nd & nd & $0 / 6$ & 3.9 \\
\hline Trichloroacetic acid & 0.4 & 5.0 & 1.23 & $6 / 6$ & 22.2 & 0.4 & 0.8 & 0.53 & $6 / 6$ & 9.2 \\
\hline Dichlorobronoacetic acid & nd & 1.6 & 0.57 & $3 / 6$ & 4.8 & nd & nd & nd & $0 / 6$ & 4.5 \\
\hline Dibromochloroacetic acid & nd & nd & nd & $0 / 6$ & 0.3 & nd & nd & nd & $0 / 6$ & 2.7 \\
\hline Tribronoacetic acid & nd & nd & nd & $0 / 6$ & nd & nd & 0.6 & 0.10 & $1 / 6$ & 1.0 \\
\hline [Halopropionic acids] & 0.2 & 0.5 & 0.28 & $6 / 6$ & 2.5 & nd & nd & nd & $0 / 6$ & 0.8 \\
\hline$\alpha$-Chloropropionic acid & nd & nd & nd & $0 / 6$ & nd & nd & nd & nd & $0 / 6$ & nd \\
\hline$\alpha$-Bromopropionic acid & nd & nd & nd & $0 / 6$ & nd & nd & nd & nd & $0 / 6$ & nd \\
\hline$\beta$-Bromopropionic acid & nd & nd & nd & $0 / 6$ & nd & nd & nd & nd & $0 / 6$ & nd \\
\hline 2,2-Dichloropropionic acid & nd & nd & nd & $0 / 6$ & 1.1 & nd & nd & nd & $0 / 6$ & 0.8 \\
\hline 2,3-Dichloropropionic acid & 0.2 & 0.5 & 0.28 & $6 / 6$ & 1.4 & nd & nd & nd & $0 / 6$ & nd \\
\hline
\end{tabular}


haloacetaldehydes, haloacetic acids and halopropionic acids, which were detected in the TE river waters, were also quantified in these water samples collected from the TA river. No chloropicrin was detected in the $\mathrm{TA}$ river waters, as with the TE river samples. Haloacetonitriles, which were not detected in the river waters, were newly quantified in the TA river samples. However, their concentrations were very low, as were the trihalomethane levels. In addition, 2,3-dichloropropionic acid was detected in the TA river waters collected in June 1996, but no halopropionic acids were quantified in the October samples. Furthermore, a num ber of brominated organic compounds were detected in the TA river waters collected in October 1996, as compared with those quantified in the June-water samples.

The total concentration of halogenated organic com pounds in the TA river waters was approximately $4 \mu \mathrm{g} / \ell$. Among these halogenated organics, the highest concentration was observed for haloacetic acids in the June-river waters, and for haloacetaldehydes in the October-water samples (Table 3 and Fig. 2), respectively. About $88 \%$ of the total amount of organic halogens detected in the TA river water samples can be ac counted for by the presence of haloacetones, haloacetal dehydes and haloacetic acids (Fig. 2). In addition, the TA river water as sampled in June 1996 was characterized by the higher concentrations of dichloroacetoaldehyde and trichloroacetic acid, as compared with those observed for other halogenated organics in the TA river samples.

Trihalomethane, haloacetones, haloacetaldehydes and haloacetic acids were detected at higher concentrations in the $\mathrm{S}$ drinking waters as sampled in June and October 1996 (Table 3). The total concentration of organic halogen compounds was $127 \mu \mathrm{g} / \ell$ in the June-water sample and $96 \mu \mathrm{g} / \ell$ in the October-sample, respectively, and these levels were found to be over 26 -times higher than those detected in the TA river waters. Marked increases in the concentrations of organic halogens were found for trihalomethanes, haloacetonitriles and haloacetic acids in the $\mathrm{S}$ drinking waters. Similar concentration levels and compositions of halogenated organics to the data presented in Table 3 and Fig. 2 were also observed in the $\mathrm{S}$ drinking water sampled in June and October 1995 (data not shown). Comparison of the total concentration of halogenated or ganic compounds between the $\mathrm{K}$ and $\mathrm{S}$ drinking waters indicates that advanced water treatment reduces the con

\section{TA River water, Jun.1996}

0.4\% Trihalomethane

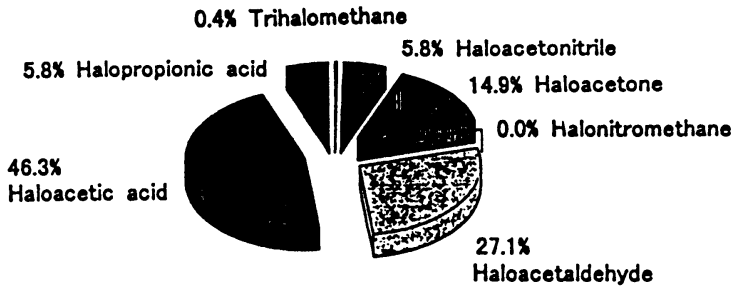

TA River water, Oct.1996

$0.0 \%$ Halopropionic acid

3.8\% Trihalomethane
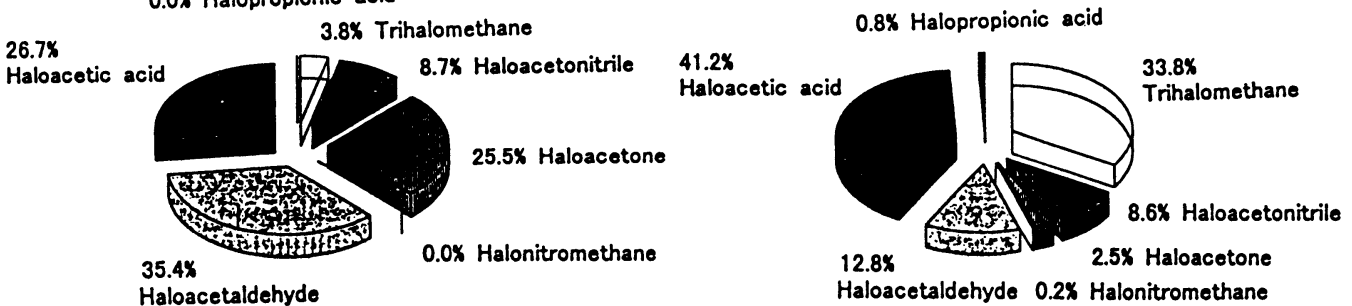

Fig. 2 Circular diagrams for concentration(\%) of each halogenated organic compound group in the TA river water and the $\mathrm{S}$ drinking water originating from the TA river 
centrations of halogenated disinfection by-products, especially those in the groups of haloacetic acids and trihalomethanes.

Usually, chlorine-treated water contains a relatively high concentration of chlorinated organic compounds as compared with other halogenated organics ${ }^{14)}$. In the present work, considerably higher concentrations of brominated compounds were found in the $\mathrm{K}$ and $\mathrm{S}$ drinking waters, although these compounds were at low concentration in the TE and TA river water samples. Over $40 \%$ of total halogenated organics quantified were brominated compounds in these drinking water samples, except for the June-S drinking water. Even higher ratios of brominated organics to total halogenated compounds were found for trihalomethanes, haloacetonitriles and haloacetic acids in these drinking waters. Several workers have demonstrated that chlorination or ozonation of surface and ground water containing bromide ions produces high concentrations of brominated trihalomethanes ${ }^{15-17)}$. However, the origin of the bromide ions in the water samples could not be clarified because of the limited samples in this survey. It has been reported that brominated organics are more mutagenic than chlorinated compounds ${ }^{18)}$, so it is particularly significant that brominated organics were found during this study of chlorine-treated water.

\section{CONCLUSIONS}

Aqueous chlorine is used to disinfect raw water destined for human consumption. The concentrations and compositions of halogenated organic compounds in the $\mathrm{TE}$ and TA river water samples and in the $\mathrm{K}$ and $\mathrm{S}$ drinking waters which originated from each river were determined by means of GC/ECD and then characterized in the present work.

A number of halogenated organic compounds were detected in the river water and drinking water samples. The total concentrations of halogenated organics were ranged from $3.45 \mu \mathrm{g} / \ell$ to $4.83 \mu \mathrm{g} / \ell$ with a mean con centration value of $4 \mu \mathrm{g} / \ell$ in the $\mathrm{TE}$ and $\mathrm{TA}$ river waters. Among these compounds, the highest concentration was observed for haloacetic acids in both the TE and $\mathrm{TA}$ river water samples. The $\mathrm{K}$ drinking water showed a total concentration of organic halogens rang. ing from $54.1 \mu \mathrm{g} / \ell$ to $69.8 \mu \mathrm{g} / \ell$, while the range of these compounds levels in the S drinking waters was from $96 \mu \mathrm{g} / \ell$ to $127 \mu \mathrm{g} / \ell$. Comparison of the total concentrations of halogenated organics between the $\mathrm{K}$ and $\mathrm{S}$ drinking waters indicated that advanced water treatment reduces the concentrations of halogenated disinfection by-products, especially those in the groups of trihalomethanes and haloacetic acids. Among these organohalogens, higher concentrations and higher ratios of brominated compounds to total organic halogens in both drinking waters were observed for trihalomethanes and haloacetic acids.

\section{REFERENCES}

1) Rook, J.J.: Production of trihalomethanes of potable water from a highly polluted rivers. Water Treat. Exam., 21, 259-274 (1972)

2) Rook, J.J.: Formation of haloforms during chlorination of natural water. Water Treat. Exam., 23, 234-243 (1974)

3) Beller, T.A., Lichtenberg, J.J. and Kromer, R.C.: Determining volatile organics at the microgram per litre levels by gas chromatography. J.A.W.W.A., 66, 703-706 (1974)

4) Cotrubo, J.A.: THMs in drinking water. Environ. Sci. Technol., 15, 268-274 (1980)

5) Bull, R.J.: Health effects of drinking water disinfectants and disinfection by-products. Environ. Sci. Technol., 16, 554a-559a (1981)

6) Onodera, S.: Characterization and determination of organic compounds in the mutagenic XAD-2 extracts of drinking water. J. Chromatogr., 557, 413-427 (1991)

7) Onodera, S., Nishikawa, T., Igarashi, K., Nishimura, A. and Suzuki, S.: Halogenated organics; Their presence and potential formation in the Tama river. J. Contam. Hydrology, 9, 155-173 (1992)

8) EI-Dib, M.A. and Ali, R.K.: Trihalomethanes and halogenated organic formation in water treatment plant. Bull. Environ. Contam. Toxicol., 49, 381-387 (1992)

9) Takahashi, Y., Nishio, T. and Morita, M.: Chlorination disinfection by-products in tap water and their formation potential in waste water. J. Environ. Chem., 7, 489-494 (1997)

10) Takahashi, Y. and Morita, M.: Simultaneous determination of halogenated chlorination disinfection by-products in water supply. J. Environ. Chem., 7, 495-506 (1997)

11) Onodera, S., Yoshimatsu, K., Saitoh, H. and Uchida, A.: Behavior of mutagenic formation from phenolic compounds in water disinfection with chlorine and 
thier mutagenic potential formation. J. Toxicol. Environ. Health, 44, 289-299 (1998)

12) Takahashi, Y., Moriyama, K. and Morita, M.: Halogenated disinfection by-products in an indoor swimming pool water. J. Environ. Chem., 8, 473-479 (1998)

13) Takahashi, Y. and Morita, M.: Unpublished data

14) Symon, S.J., Beller, T.A., Craswell, J.K., Demarko, J., Kropp, K.L., Robeck, G.G., Seeger, D.R., Slocum, C.J., Smith, B.L. and Steven, A.A.: National organic reconnaissance survey for halogenated organics. J.A. W.W.A., 67, 634-647 (1975)

15) Ventuna, F. and Rivera, J.: Factors influencing the high content of brominated trihalomethanes in Barcelona's water supply(Spain). Bull. Environ.
Contam. Toxicol. 35, 73-81 (1985)

16) Fayad, N.M. and Iqbal, S.: Analysis of drinking water for the detection of trihalomethanes. Bull. Environ. Contam. Toxicol., 35, 576-582 (1985)

17) Cooper, W.J., Amy, G.L., Moore, C.A. and Zika, R.G.: Bromoform formation in ozonated groundwater containing bromide and humic substances. Ozone, 8, 63-76 (1986)

18) Bujis, W., Van der Gen, S., Mohn, G.R. and Breimer, D.D.: The direct mutagenic activity of $\alpha$, $\omega$-dihalogenoalkanes in Salmonella typhimurium; Strong correlation between chemical properties and mutagenic activity. Mutation Res., 141, 11-14 (1984) 